\title{
MALIGNANT JUVENILE AND ADULT OVARIAN GRANULOSA CELL TUMORS IN PEDIATRIC PATIENTS - REPORT OF TWO CASES
}

\author{
Usiwoma-Okeroghene Ataikiru ${ }^{1,2}$, Emil-Radu Iacob ${ }^{1,2}$, Călin-Marius Popoiu ${ }^{1,2}$, Păun Fuicu ${ }^{1,2}$, \\ Rodica Heredea $^{3}$, Ingrith Miron ${ }^{4,5}$, Eugen Sorin Boia ${ }^{1,2}$
}

\section{Abstract}

Juvenile ovarian granulosa cell tumor is a sex chord stromal tumor derived from granulosa cells. It rarely occurs in children. Although it is usually classified as a benign tumor in children due to its good prognosis after surgical intervention, it is a malignant tumor and can be deadly, especially if recurrence occurs. We report two rare cases. The first one is a five-year-old girl with a malignant juvenile ovarian granulosa cell tumor stage 3 FIGO, presenting with abdominal pain in the inferior part of the abdomen and very early pubertal development. On physical examination, she was at stage two puberty. The second case is a 12 years old girl presenting with two periods monthly. An $8.3 / 5.4 \mathrm{~cm}$ mass was found at the pelvic region on ultrasound examination. Exploratory laparoscopy with histological examination led to the diagnosis of stage 2A FIGO, combined juvenile and adult ovarian granulosa cell tumor. Conclusion: Precocious puberty accompanying abdominal pain or more than a period in a month is a pointer to juvenile and adult ovarian granulosa cell tumor requiring immediate investigations and patient management. Early diagnosis with the assistance of inhibin test and a FISH test of p53(17p13) aids better management of patients with Juvenile ovarian granulosa cell tumor, preventing tumor recurrence for a favorable outcome. Juvenile and adult ovarian granulosa cell tumors in pediatric female patients can present in different forms but gearing towards menstruation abnormalities.

Keywords: precocious puberty, juvenile ovarian granulosa cell tumor, adult granulosa cell tumor, irregular menstrual cycle, gene P53

\section{Introduction}

The incidence of malignant tumors in prepubertal girls is 0.102 per 100.000 girls [1]. Granulosa cell tumor is a malignant sex cord-stromal ovarian tumor classified into adult-type or juvenile-type, which is usually at stage 1 in $90 \%$ of cases [2]. Pediatric patients account for $4-5 \%$ of ovarian granulosa cell tumors, which are responsible for $10 \%$ of very early puberty in prepubertal girls $[2,3]$. The factors that contribute to poor prognosis in these patients include: high tumor stage, high tumor marker level, large tumor, late diagnosis, presence of cancer-related genetic abnormalities, and recurrence that mainly occurs after puberty [4]. We present a rare case of a 12 years old girl with both juvenile and adult ovarian granulosa cell tumor staged $2 \mathrm{~A}$ and a second case of a malignant juvenile ovarian granulosa cell tumor stage 3 in a five years old girl presenting with abdominal pain and very early pubertal development, although normal puberty starts in girls between 8-9 years old [5]. Both patients were diagnosed and managed with surgical intervention and chemotherapy.

\section{Case 1}

A 5 years old girl presented at our hospital with complaints of abdominal pain for two months and loss of appetite. She had no significant medical or family history, except repeated urinary infection from infancy and dental caries. She was not on any medication. She was the first child to a 22 years old mother, while the father was 30 years old. She weighed $3300 \mathrm{~g}$ at birth with APGAR score of 9, delivered at nine months, naturally and in cranial presentation. The patient was breastfed for one week before started on artificial milk and diversification, taking all vaccine required and vitamin D. On physical examination, she weighed $20 \mathrm{~kg}$ and had a height of $117 \mathrm{~cm}$, afebrile, with precocious puberty signs: thelarche with eminent breast areola-Tanner 2 and some fine hair strands in the pubic region -Tanner 2. The abdomen was slightly distended in volume and painful at superficial palpation in the left iliac region, with a mass detected at deep palpation.

${ }^{1}$ Department of Pediatric Surgery and Orthopedics, "Victor Babes" University of Medicine and Pharmacy Timisoara, Romania.

${ }^{2}$ Department of Pediatric Surgery and Orthopedics "Louis Turcanu" Emergency Children's Hospital Timisoara, Romania. ${ }^{3}$ Department of Pathological Anatomy "Louis Turcanu" Emergency Children's Hospital Timisoara, Romania.

${ }^{4}$ Department of Pediatrics, University of Medicine and Pharmacy Grigore T Popa, Iasi Romania

${ }^{5}$ Department of Pediatric Hematology and Oncology, St Mary Clinical Emergency Hospital for Children. Iasi, Romania E-mail: usiwomaataikiru@yahoo.com,radueiacob@umft.ro,mcpopoiu@yahoo.com, dr.fuicupaun@yahoo.com, heredea.rodica@yahoo.com, ingridmiron@hotmail.com, boiaeugen@yahoo.com 


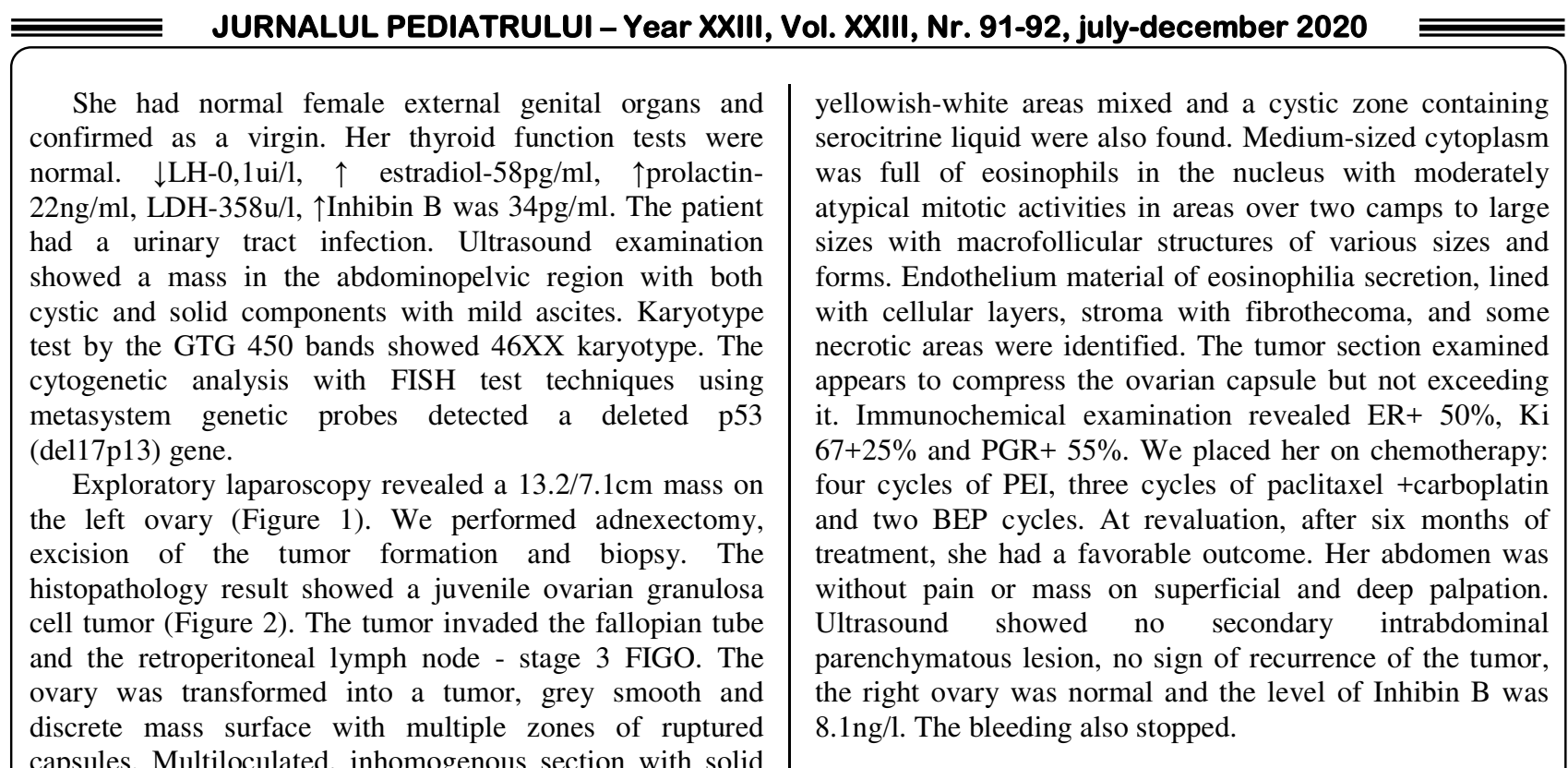

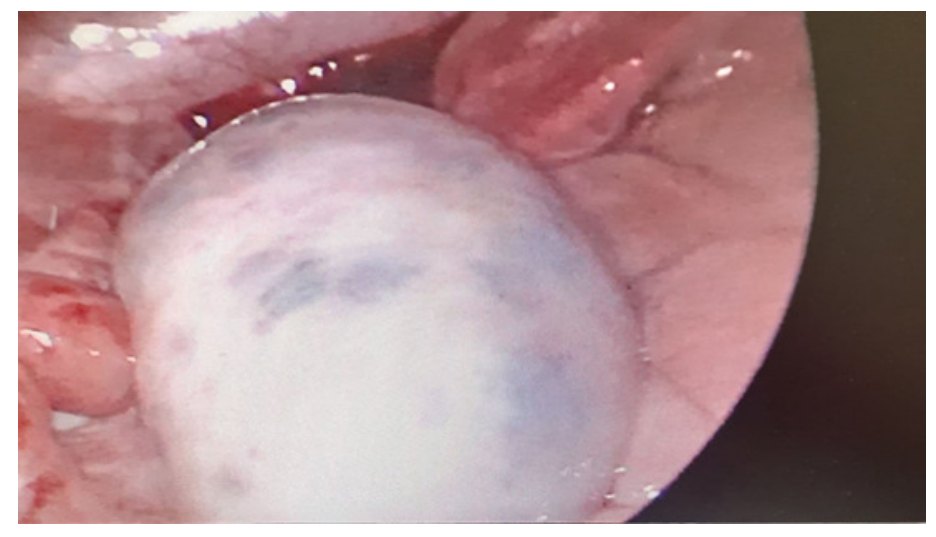

Figure 1. Intraoperative image of the ovary with Granulosa cell tumor.

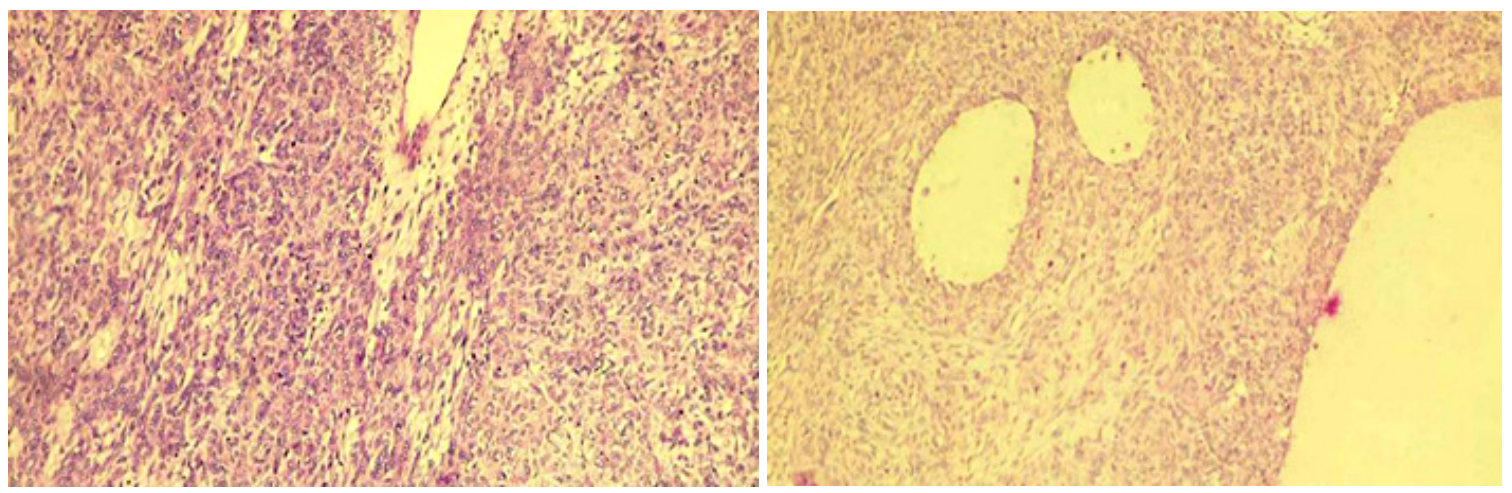

Figure 2. Histopathology of Granulosa cell tumor Hematoxylin-Eosin stains 20X.

\section{Case 2}

A 12 years old girl without any significant family or personal medical history, one year after menarche, presented at our hospital with complaints of irregular menstrual cycles, having two periods in a month. She was placed on vitex agnus-castus and progesterone, but symptoms persisted after five months. On physical examination, she weighed $45 \mathrm{~kg}$ and had a height of $165 \mathrm{~cm}$. No abdominal pain or mass at superficial and deep palpation of the abdomen were found. She had normal 


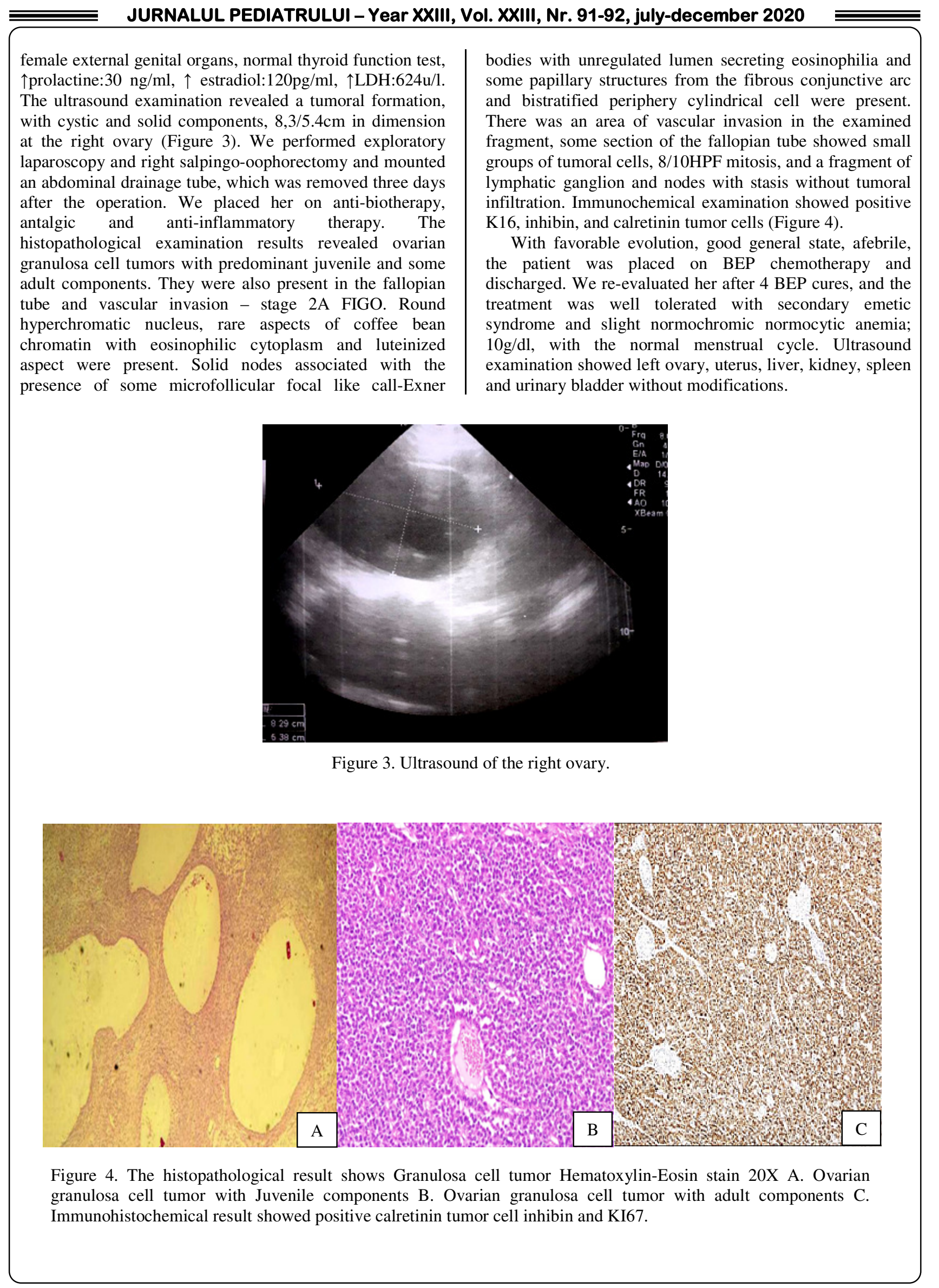




\section{Discussion}

In patients with granulosa cell tumors, the tumor usually secrets estrogen hormone because the action of cytochrome P450 aromatase is not controlled [4], hence estrogen levels are elevated. The presented cases show that when this pathology appears in prepubertal girls, it can cause very early puberty, while when it appears in pubertal girls, it can cause multiple periods in a month. According to literature precocious puberty is when secondary sexual characteristics are present in a girl before eight years and can be a pointer to the presence of a tumor, such as juvenile ovarian granulosa cell tumor [5]. Mutations of AKT1 and FOXL2 genes have been identified in juvenile and adult granulosa ovarian cell tumors. In a study, Follicular Stimulating Hormones in an eight-year-old girl were responsible of causing juvenile ovarian granulosa cell tumor [6,7]. CallExner bodies, coffee-bean, groove nucleus, or microfollicular pattern are present in adult OGCT, but macrofollicular space and round nuclei are present in the Juvenile type. The juvenile type grows aggressively in comparison to the adult one [8,9]. A report shows that ovarian granulosa cell tumor can combine with other tumors like cystadenomas [10]. Mitosis greater than 4/10HPF or a high level of Inhibin B, a tumor marker useful for detecting OGCT, have both proved to be related to the recurrence of ovarian granulosa cell tumor, which results in poor prognosis $[11,12]$. The inhibin value of the first patient was higher than the average level of $26.5 \mathrm{pg} / \mathrm{ml}$ in girls at pubertal stage 1 (average age 9), and estradiol level was higher than 40.5, which is the average level for girls at pubertal stage 2 with an average age of 11,4 years old [13]. The 2nd patient returned after four cycles of BEP with a better outcome and had a lower inhibin level, unlike the 1st patient who was on four cycles of PEI, three cycles of paclitaxel +carboplatin, and two cycles of BEP for more than six months, which can be attributed to the high tumor stage and deletion of Tp53 gene. Tp53 gene protein is a tumor suppressor which, if altered, leads to poor prognosis, especially if at stage II-IV or with large tumor sizes like 10$15 \mathrm{~cm}$, hence further adjuvant chemotherapy after surgical intervention is given to improve the patient's outcome and prevent recurrence $[14,15]$. Malignancy aggression, the affected organs, or tumor size determines the treatment options like tumor excision, adnexectomy, gonadectomy, or hysterectomy, with the efforts to save the gonads and the goal to save the patient's life. Our patients show that juvenile ovarian granulosa cell tumors in females can be present in different forms but gearing towards abnormalities in menstruation according to the given age.

\section{Conclusion}

A patient presenting with precocious puberty accompanying abdominal pain is a pointer of juvenile ovarian granulosa cell tumor requiring further investigations and immediate intervention. Early diagnosis with the assistance of inhibin B and a FISH test of Tp53 helps in deciding the best choice of management of patients with juvenile ovarian granulosa cell tumor preventing recurrence for a better outcome. Juvenile ovarian granulosa cell tumor in pediatric female patients can present in different forms, but gearing towards abnormalities in menstruation.

\section{Conflicts of interest}

All authors have no conflicts of interest to declare.

\section{References}

1. Ali SW, Ali NN, Ashraf MS, et al. Juvenile granulosa cell tumor in a nine year old. Journal of Pediatric Surgery Case Reports. 2020 Apr 1;55:101397.

2. Rusterholz KR, MacDonald W. An unusual case of juvenile granulosa cell tumor of the ovary. Radiology case reports. 2009 Jan 1;4(1):178.

3. Nikumbh DB, Suryawanshi KH, Chitale AM, et al. Ovarian juvenile granulosa cell tumour in childhood: uncommon gynecological malignancy. Journal of clinical and diagnostic research: JCDR. 2014 Oct;8(10):FL01.

4. Kottarathil VD, Antony MA, Nair IR, Pavithran K. Recent advances in granulosa cell tumor ovary: a review. Indian journal of surgical oncology. 2013 Mar 1;4(1):37-47.

5. Lacourt P, Soto J, Rumié $\mathrm{H}$, et al. Granulosa cell ovarian tumor: precocious puberty in infant less than 1 year of age. Case report. Rev Chil Pediatr. 2017 Dec 1;88(6):792-7.

6. Auguste A, Bessière L, Todeschini AL, Caburet S, Sarnacki S, Prat J, D'angelo E, De La Grange P, Ariste
O, Lemoine F, Legois B. Molecular analyses of juvenile granulosa cell tumors bearing AKT1 mutations provide insights into tumor biology and therapeutic leads. Human molecular genetics. 2015 Dec 1;24(23):668798.

7. Calcaterra V, Nakib G, Pelizzo G, Rundo B, Rispoli GA, Boghen S, Bonetti F, Del Monte B, Gertosio C, Larizza D. Central precocious puberty and granulosa cell ovarian tumor in an 8-year old female. Pediatric reports. 2013 Jul 29;5(3).

8. Raghavan D, Ahluwalia MS, Blanke CD, Brown J, Kim ES, Reaman GH, Sekeres MA, editors. Textbook of uncommon cancer. John Wiley \& Sons; 2017 May 8.

9. Calaminus G, Wessalowski R, Harms D, Göbel U. Juvenile granulosa cell tumors of the ovary in children and adolescents: results from 33 patients registered in a prospective cooperative study. Gynecol Oncol. 1997;65:447-52

10. McKenna M, Kenny B, Dorman G, McCluggage WG. Combined adult granulosa cell tumor and mucinous cystadenoma of the ovary: granulosa cell tumor with 


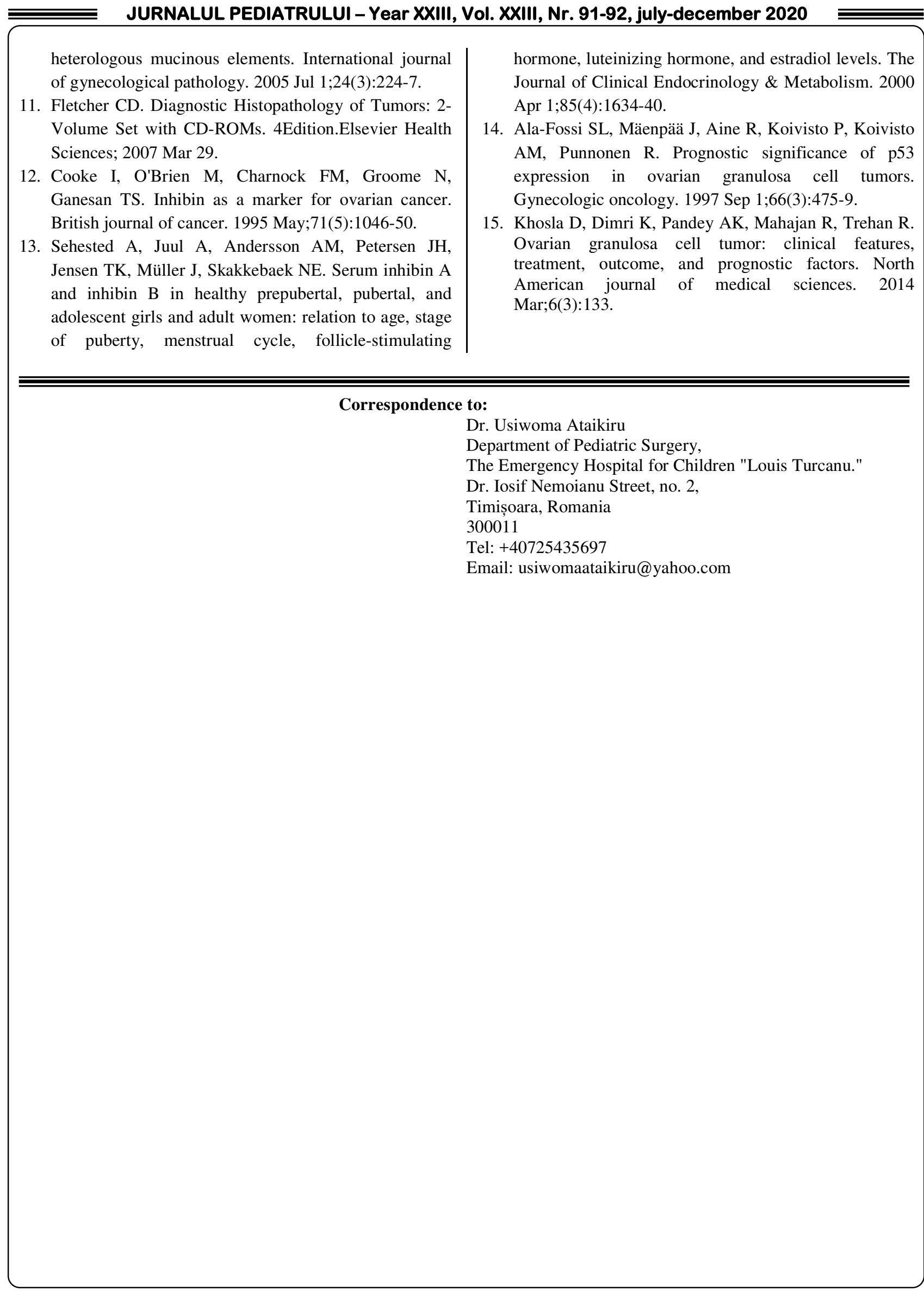

